\title{
Social-psychological predictors of self-reported actual and intended physical activity in a university workforce sample
}

\author{
Stuart Biddle BEd MSc PhD C.Psychol, Marios Goudas BA and Angela Page BA \\ School of Education, University of Exeter, Exeter, UK
}

\begin{abstract}
This study investigated the social-psychological predictors of self-reported actual and intended physical activity in a university workforce sample. Based on the 'Theory of Planned Behaviour', but with additional variables of benefits, barriers and self-efficacy, it was found that both intended and actual activity could be predicted but only when strenuous activity was considered. In addition, the predictors were different for men and women. Specifically, the best predictors of intention to exercise were attitude, perceived control, benefits and self-efficacy for women, but. only attitude for men. Predicting selfreported strenuous activity for women were intention and self-efficacy, and for men intention and attitude. Theoretical and practical implications for attitude research and exercise promotion are discussed.
\end{abstract}

Keywords: Attitude, exercise, physical activity, selfefficacy

The potential contribution of physical activity (PA) to various indices of health is now well documented ${ }^{1}$, but rather less is known about how best to promote such behaviour. One social-psychological approach that has received a great deal of attention in recent years has been that of Fishbein and Ajzen's 'Theory of Reasoned Action' (TRA) ${ }^{2}$. If we use exercise as an illustration, Fishbein and Ajzen propose that participation in exercise will best be predicted by a measure of intention to exercise which, in turn, is predicted by attitudes towards exercise and social normative influences on exercise, such as the beliefs of 'significant others'. Such a model has received attention in exercise contexts ${ }^{3,4}$ and has usually managed to explain between 20 and $40 \%$ of the variance in actual or intended exercise. Unfortunately, many of the studies have measured only intention rather than the behaviour itself.

Ajzen ${ }^{5,6}$ has argued that the TRA holds true when the behaviour being investigated is under volitional control. In cases where control is not possible or is incomplete, he proposes that a measure of 'perceived behavioural control' (PBC) will enhance the prediction of behaviour. The TRA, plus PBC, have been

Address for correspondence: Stuart Biddle PhD, School of Education, University of Exeter, Exeter EX1 2LU, UK

(C) 1994 Butterworth-Heinemann Ltd

0306-3674/94/030160-04 labelled the Theory of Planned Behaviour (TPB). Recent research on patterns of health behaviour (e.g. exercise $^{7}$, sport ${ }^{8}$ and weight $\operatorname{control}^{9}$ ), has supported the TPB.

Criticisms of the TPB centre on the definition and measurement of the construct of PBC and the utility of additional variables in predicting intentions and behaviour ${ }^{3}$. The similarity of PBC to constructs such as self-efficacy (situational self-confidence to initiate the desired behaviour) ${ }^{10}$ or perceived barriers requires that future research should investigate the extent to which these contribute independently to the prediction of physical activity (PA). Indeed, recent studies on the measurement of perceived benefits and barriers to physical activity ${ }^{11,12}$ have shown that these constructs may also be important factors in determining whether people exercise or not.

The purpose of this study, therefore, was to investigate the extent to which variables from the Theory of Planned Behaviour, as well as self-efficacy and perceived barriers and benefits, would predict self-reported PA levels, and intention to be physically active.

\section{Method}

All full-time employees on a university campus in the south-west of England comprised the initial sample. The campus houses a large single academic department and is separate from the campus that houses most other departments of the same university. Subjects in the sample were sent a questionnaire through the internal mail system. This included 'academic and research staff', 'academic-related staff', 'secretarial-clerical staff' and 'technical staff'.

From an initial mailing, $131(70 \%)$ questionnaires were returned (men $n=63$; women $n=68$ ).

\section{Instrumentation}

The questionnaire comprised three sections: selfreported physical activity; social-psychological factors; and personal information.

\section{Self-reported physical activity}

Physical activity was assessed with a modified version of Godin and Shephard's 'Leisure-time 
exercise questionnaire' $\left(\right.$ LTEQ) ${ }^{13}$. Since the LTEQ only includes activity in 'free (leisure) time', it was modified to include all activity, at work, home and 'free time', so as to be more representative of total activity. Subjects were requested to consider 'an average week' (7 days) and to indicate the number of times they usually engage in at least $15 \mathrm{~min}$ of 'strenuous', 'moderate' and 'light' physical activity. Each category was defined and illustrated with examples. As far as possible, the examples included activities appropriate for formal 'exercises' (e.g. sports) and others (e.g. gardening, manual work, etc), as well as for men and women. A total activity index can be calculated by multiplying the categories as follows: strenuous $(\times 9)$, moderate $(\times 5)$ and light ( $\times 3)$. Individual categories can also be investigated separately (e.g. strenuous). The weightings correspond to anticipated intensities or 'metabolic equivalent' (MET) values proposed by Godin and Shephard ${ }^{13}$.

\section{Social-psychological variables}

To provide a clear target behaviour, as recommended by Ajzen and Fishbein ${ }^{14}$, the word 'exercise' was used in the section asking questions concerning social-psychological factors. Subjects were asked questions concerning their intention to exercise (four questions); their attitude to exercise (one question); their perceived control over exercise participation (three questions); social norm influences (one question each for senior colleagues, friends, co-workers, and family); self-efficacy (three questions for confidence in being able to exercise over the next week, month and 6 months respectively); benefits and barriers in exercise (five barriers and five benefits identified by Sechrist et al. ${ }^{11}$ and Steinhardt and Dishman ${ }^{12}$ ).

All variables were assessed on five-point scales with the exception of self-efficacy. This was assessed on an eight-point scale to allow for more variability in confidence ratings.

\section{Personal information}

The final section of the questionnaire asked each subject their age, sex and occupational group (within the institution), based on the categories listed earlier.

\section{Results}

\section{Reliability of subscales}

Cronbach's coefficient $\alpha$ was computed to assess scale internal reliability where appropriate. Subscales were shown to have good internal reliability (selfefficacy, $\alpha=0.91$; perceived control, $\alpha=0.81$; intention, $\alpha=0.94$ ). The measures of barriers, benefits and subjective norm were constructed with individual items in mind and therefore internal consistency was not considered necessary.

\section{Descriptive statistics}

Table 1 shows the descriptive statistics for the whole sample as well as men and women separately. It
Table 1. Descriptive statistics for physical activity and psychological variables for men, women and all subjects

$A / I(\mathrm{n}=131) \quad$ Men $(\mathrm{n}=63)$ Women $(\mathrm{n}=68)$

$\begin{array}{lccc}\text { Physical activity } & & & \\ \quad \text { Strenuous } & 1.60(1.92) & 1.68(1.98) & 1.55(1.89) \\ \text { Moderate } & 3.44(2.34) & 3.47(2.37) & 3.34(2.33) \\ \text { Light } & 4.77(2.64) & 4.74(2.72) & 4.76(2.61) \\ \quad \text { Total index } & 49.30(28.37) & 50.12(30.06) & 48.48(26.80) \\ & & & \\ \text { Psychological } & & & \\ \text { Intention } & 3.08(1.36) & 3.05(1.36) & 3.12(1.38) \\ \text { Attitude } & 4.25(0.92) & 4.07(0.89) & 4.42(0.92) \\ \text { Social norm } & 3.11(1.03) & 3.13(1.00) & 3.07(1.06) \\ \text { Control } & 3.99(0.98) & 3.94(0.92) & 4.04(1.04) \\ \text { Barriers } & 2.19(0.64) & 2.16(0.63) & 2.23(0.66) \\ \text { Benefits } & 3.21(0.74) & 3.08(0.69) & 3.40(0.75) \\ \text { Self-efficacy } & 4.65(2.35) & 4.75(2.46) & 4.52(2.25)\end{array}$

Values are mean(s.d.)

shows that men were slightly more active than women, but these differences were not significant ( $t$ test; $P>0.05$ ). The total activity index was slightly higher than that reported by Godin and Shephard ${ }^{13}$ and this probably reflects the inclusion of all activity and not just that performed in leisure-time.

For the social-psychological variables, it can be seen that the sample as a whole had a positive attitude towards exercise, but only a moderate intention to participate. The sample was also moderately confident in being able to participate in exercise, perceived barriers to be relatively small and felt largely in control of their ability to exercise. Gender differences were assessed by Hotelling's $T^{2}$. Results showed a multivariate trend only $\left[T^{2}=0.13\right.$; $F(6,90)=1.96 ; \quad P<0.08]$, with post-hoc univariate analyses showing differences $(P<0.05)$ on attitude and benefits. In both cases, women had higher scores than men.

Correlations between the main variables are given in Table 2. These show that intention to exercise is correlated with attitude, perceived behavioural control, perceived benefits, and self-efficacy. However, the total activity index is largely uncorrelated with the psychological variables, although the measure of participation in strenuous physical activity was correlated with attitude, perceived behavioural control, benefits and self-efficacy.

Table 2. Correlations between social-psychological variables and intention and physical activity measures

\begin{tabular}{lccc}
\hline & Intention & $P A$ (index) & $P A$ (strenuous) \\
\hline & & & \\
Attitude & $0.55^{*}$ & -0.02 & $0.30 \dagger$ \\
Social norm & -0.20 & 0.10 & -0.12 \\
Control & $0.37^{*}$ & -0.08 & $0.35^{*}$ \\
Barriers & -0.14 & -0.02 & -0.14 \\
Benefits & $0.42^{*}$ & -0.06 & $0.36^{*}$ \\
Self-efficacy & $0.64^{*}$ & $-0.22 \dagger$ & $0.52^{*}$ \\
& & & \\
\hline
\end{tabular}

${ }^{*} P<0.01 ;+P<0.05$ 


\section{Prediction of intention}

Although we have data on self-reported physical activity, we thought it would be informative to predict both activity and intention. This is for two reasons. First, many other studies have investigated only intention and so this allows a comparison with previous research to be made. Second, since many people working in exercise and health promotion will often assess intentions, a comparison of predictors of both intention and actual (self-reported) physical activity might be informative.

Given that we are basing our study on the Theory of Planned Behaviour, but with additional variables to see if they assist in prediction, hierarchical multiple regression is the most appropriate form of analysis ${ }^{15}$. Based on a priori reasoning and known research finding $s^{3}$, the independent variables were entered in the following order: attitude, social norm, perceived control, barriers, benefits and self-efficacy.

Given the gender differences noted earlier, separate analyses were undertaken for men and women. For women, $62 \%$ of the variance in intention was explained by these variables. Those adding significantly to the equation were attitude, perceived control, benefits and self-efficacy. For men, 52\% of the variance in intention was explained, with $46 \%$ of the total variance attributed to attitude alone (see Table 3).

\section{Prediction of physical activity}

The same analyses were employed to predict PA levels of men and women. Hierarchical multiple regression, using the total PA index as the criterion variable, showed that none of the social-psychological variables predicted PA. However, the questionnaire was constructed to ask about exercise. Therefore, based on Ajzen and Fishbein's ${ }^{14}$ notion of correspondence between the subject of the attitude

Table 3. Hierarchical multiple regression analysis for men and women predicting intention to exercise, and self-reported strenuous physical activity

\begin{tabular}{lllll}
\hline & \multicolumn{2}{c}{ Women } & \multicolumn{2}{c}{ Men } \\
& $\mathrm{R}^{2}$ & F change & $\mathrm{R}^{2}$ & F change \\
& & & & \\
& & & & \\
Intention & & & & \\
1. Attitude & 0.17 & $4.58^{*}$ & 0.46 & $38.58^{*}$ \\
2. Social norm & 0.18 & 0.14 & 0.46 & 0.00 \\
3. Control & 0.29 & $6.40^{*}$ & 0.47 & 0.32 \\
4. Barriers & 0.33 & 2.60 & 0.49 & 1.86 \\
5. Benefits & 0.51 & $14.90^{*}$ & 0.49 & 0.00 \\
6. Self-efficacy & 0.62 & $10.49^{*}$ & 0.52 & 2.41 \\
& & & & \\
Strenuous physical activity & & & & \\
1. Intention & 0.17 & $8.48^{*}$ & 0.21 & $11.81^{*}$ \\
2. Attitude & 0.19 & 0.80 & 0.32 & $6.93+$ \\
3. Social norm & 0.20 & 0.21 & 0.33 & 0.65 \\
4. Control & 0.25 & 2.68 & 0.34 & 0.29 \\
5. Barriers & 0.25 & 0.24 & 0.34 & 0.04 \\
6. Benefits & 0.30 & 2.69 & 0.34 & 0.04 \\
7. Self-efficacy & 0.32 & $3.16 \neq$ & 0.38 & 2.01 \\
& & & & \\
\hline
\end{tabular}

Changes in $F:{ }^{*} P<0.01 ;+P<0.05 ; \ddagger P=0.08$ questions and the actual behaviour assessed, results for self-reported strenuous PA were analysed. The results showed that the social-psychological variables were able to predict participation in this type of activity.

For women, $32 \%$ of the variance in strenuous PA was explained. However, only the $F$ values for intention and self-efficacy changed significantly on entering the equation (see Table 3). For men, the picture was slightly different. Variance accounted for was $38 \%$, with intention and attitude showing significant changes in $F$ values on entering the analysis (see Table 3).

\section{Discussion}

This study was an investigation into social-psychological correlates of both intended and self-reported physical activity based on Ajzen's Theory of Planned Behaviour ${ }^{5}$. Clearly the sample is oriented towards individuals with higher educational levels, and we do not wish to generalize beyond such a group. Nevertheless, the results showed that a substantial amount of the scores in intention to exercise can be predicted from social-psychological variables for such a sample. However, there were gender differences such that intention for men was best predicted by attitude, but for women intention was best predicted by the variables of the TPB (at least attitude and perceived behavioural control), as well as benefits and self-efficacy. However, when selfreported physical activity was analysed, the social-psychological variables were not predictive. This is probably due to a lack of correspondence between the target behaviour patterns being assessed. The social-psychological variables refer to exercise whereas the PA index is a combination of strenuous, moderate and mild activity. This 'total' activity score lacks correspondence with the social-psychological questions and thus violates recommendations of Ajzen and Fishbein ${ }^{14}$.

To achieve correspondence between the variables, strenuous PA scores were analysed. This time the social-psychological variables were predictive, accounting for $32 \%$ and $38 \%$ of the variance for women and men respectively - much smaller amounts than for intention. However, for women, the variables of the TPB added little to prediction after intention scores, with only self-efficacy showing as a variable of added importance. For men, attitude added significantly to the prediction equation after intention.

This study, therefore, has highlighted three issues which may be of importance for both theory and practice. As far as theoretical issues are concerned, intention and self-reported 'actual' strenuous PA are not synonymous. By analysing only the predictors of intention one can achieve an over-optimistic estimate of 'actual' PA. For the TPB, intention is predicted by the attitudinal component. However, the addition of perceived behavioural control is significant only for women. Similarly, self-efficacy and perceived benefits of exercise appear to be strong factors associated 
with intention for women, but not men. The similarity between the variables of PBC and selfefficacy needs to be determined in future studies. We obtained a significant correlation across the whole sample for these two variables $(r=0.40 ; P<0.01)$. The Theory of Planned Behaviour has been supported more for women in the prediction of intention than for men or women in the prediction of strenuous PA. For the latter, it appears that $P B C$ is not a predictor.

The second theoretical issue is associated with correspondence between variables. This study has shown clearly that if prediction is to be achieved, the behaviour referred to in the questions must correspond closely to that assessed as the dependent variable. Whether the total PA index is not predicted by these social-psychological variables will still need to be assessed. However, to test this the questions must focus on habitual PA and not just exercise.

From a practical standpoint, the gender differences noted in this study might provide important information for those wishing to promote exercise as health-related behaviour. The results suggest that intention and attitude are the strongest predictors of exercise for men, whereas for women the best predictors are intention, and self-efficacy. It appears that these results are consistent with previous research on the importance of self-confidence in physical activity settings for women ${ }^{3,16}$. As such, those promoting exercise will need to address ways of enhancing confidence of women in exercise settings.

\section{Acknowledgement}

The support of Somerset Health Authority in this research is gratefully acknowledged.

\section{References}

1 Bouchard C, Shephard RJ, Stephens T, Sutton JR, McPherson $\mathrm{BD}$, eds. Exercise, Fitness and Health: A Consensus of Current Knowledge. Champaign, Illinois, USA: Human Kinetics, 1990.

2 Fishbein M, Ajzen I. Belief, Attitude, Intention and Behaviour: An Introduction to Theory and Research. Reading, Massachusetts, USA: Addison-Wesley, 1975.

3 Biddle SJH, Mutrie N. Psychology of Physical Activity and Exercise: A Health-Related Perspective. London, UK: Springer, 1991.

4 Godin G, Shephard RJ. Use of attitude-behaviour models in exercise promotion. Sports Med 1990; 10: 103-21.

5 Ajzen I. From intentions to actions: a theory of planned behaviour. In: Kuhl J, Beckmann J, eds. Action Control: From Cognition to Behaviour. Berlin, Germany: Springer, 1985: 11-39.

6 Ajzen I. Attitudes, Personality and Behaviour. Milton Keynes, UK: Open University, 1988.

7 Gatch CL, Kendzierski D. Predicting exercise intentions: the theory of planned behaviour. Res Q Exerc Sport 1990; 61: $100-2$.

8 Theodorakis Y. Prediction of athletic participation: a test of planned behaviour theory. Percept Mot Skills 1992; 74: 371-9.

9 Schifter DE, Ajzen I. Intention, perceived control and weight loss: an application of the theory of planned behaviour. J Pers Soc Psychol 1985; 49: 843-51.

10 Bandura A. Social Foundations of Thought and Action. Englewood Cliffs, New Jersey, USA: Prentice Hall, 1986.

11 Sechrist KR, Walker SN, Pender NJ. Development and psychometric evaluation of the exercise benefits/barriers scale. Res Nurs Health 1987; 10: 357-65.

12 Steinhardt MA, Dishman RK. Reliability and validity of expected outcomes and barriers for habitual physical activity. J Occup Med 1989; 31: 536-46.

13 Godin G, Shephard RJ. A simple method to assess exercise behaviour in the community. Canadian Journal of Applied Sport Sciences 1985; 10: 141-6.

14 Ajzen I, Fishbein M. Attitude-behaviour relations: a theoretical analysis and review of empirical research. Psychol Bull 1977; 84: 888-918.

15 Tabachnick BG, Fidell LS. Using Multivariate Statistics, 2nd ed. New York, USA: Harper Collins, 1989.

16 Corbin CB. Self-confidence of females in sports and physical activity. Clin Sports Med 1984; 3: 895-908.

The International Olympic Committee announces the foundation of the IOC Olympic Prize for outstanding research in the field of science applied to human movement, physical exercise and sport. The prize may be awarded in the biological, medical, physical or psychological sciences. The pize will be awarded every second year, to coincide with the summer and winter Olympics, and comprises a medal, a diploma and US\$250,000 cash. The first award will be made at Atlanta in 1996. Details may be obtained from IOC Medical Commission, Château de Vidy, CH-1007 Lausanne, Switzerland (Tel: 41.21.621.61.11; Fax: 41.21.624.61.66). 